\title{
MORFOLOGIA URBANA E APROPRIAÇÃO DO ESPAÇO: PERCEPÇÃO URBANA E IMAGINÁRIO SOBRE ÁREAS DE HABITAÇÃO DE INTERESSE SOCIAL POR HABITANTES DA CIDADE LEGAL EM ITAJAÍ/SC.
}

\author{
Luciana Noronha Pereira ${ }^{1}$
}

Clarissa Ganzer S. ${ }^{2}$

RESUMO: Esta pesquisa busca compreender como a morfologia urbana e sua apropriação em áreas de Habitação de Interesse Social e nas áreas Nossa Senhora das Graças e Promorar II (Itajaí/SC), encosta de morro e fundo de vale, respectivamente, é percebida pelos moradores da cidade legal em Itajaí/SC, buscando também identificar outros fatores que podem interferir nesta percepção, assim como o que esses residentes de outros bairros entendem por Habitação de Interesse Social. Este trabalho é

\footnotetext{
${ }^{1}$ Arquiteta e Urbanista pela Universidade Federal do Pará. Mestrado em Turismo e Hotelaria na Universidade do Vale do Itajaí. Doutorando em Arquitetura e Urbanismo na Universidade Federal de Santa Catarina. Professora do curso de Arquitetura e Urbanismo da Univali. luciananoronha@univali.br ${ }^{2}$ Jornalista pela Universidade de Passo Fundo. Graduando de Arquitetura e Urbanismo na Universidade do Vale do Itajaí. clarissagzr@gmail.com
} 


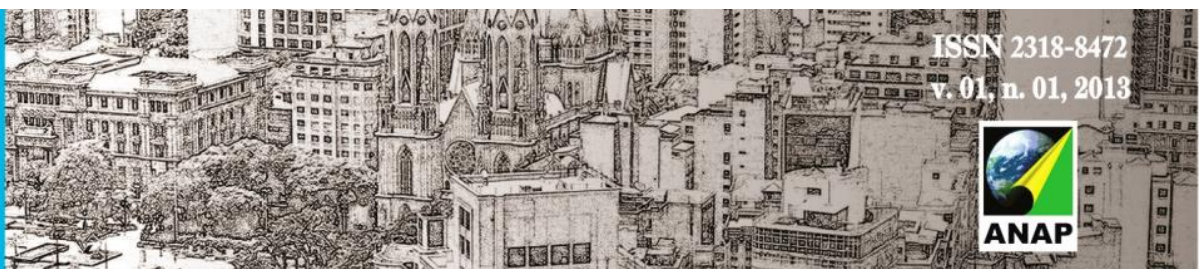

Revista Nacional de

Gerenciamento de Cidades

continuação de duas pesquisas anteriores que atentaram-se a discutir a morfologia e tipologia urbana e a apropriação do espaço pelos próprios moradores. A partir desses trabalhos, revelou-se a necessidade de entender como os residentes de outros bairros enxergam esses locais e o que faz parte do imaginário coletivo ao referir-se a HIS. Enquanto os residentes das áreas pesquisadas relatam o estreito laço de identificação e orgulho do lugar onde vivem, os moradores da cidade legal demonstram desconhecimento sobre o que são HIS e, especificamente, sobre as comunidades analisadas. A precariedade de infraestrutura urbana das comunidades, bem como a criminalidade são recorrentes para caracterizar estes locais, muitas vezes indicando conceito preconcebidos. A metodologia adotada nesta pesquisa apropriou-se de estratégias para a compreensão da percepção, imaginário e significado com o auxílio da semiótica e do Discurso do Sujeito Coletivo - DSC, através de entrevistas semiestruturadas com moradores da cidade legal de Itajaí. Ainda, utilizou de leitura cartográfica e coleta de dados secundários, tais como renda e taxas de criminalidade.

Palavras-Chave: Morfologia Urbana. Percepção Ambiental. Habitação de Interesse Social. 


\section{INTRODUÇÃO}

O sistema habitacional brasileiro ainda hoje repete modelos de alternativas para áreas de Habitação de Interesse Social de décadas passadas. As habitações, sejam casas ou apartamentos, dedicadas a HIS geralmente localizam-se na periferia das cidades, não expressam diversidade em sua tipologia e, muitas vezes, apresentam condições de infraestrutura e serviços públicos fundamentais insuficientes. A apropriação urbana e a forma como ela acontece e se estrutura é determinante na maneira de como o indivíduo se relaciona com o espaço em que vive e com a sociedade em que está inserido. Dessa forma, muitos residentes de HIS ou em áreas inapropriadas e de risco, como encostas de morro e fundo de vale, são associados a todo tipo de carências e criminalidade que são frequentemente relacionada a estas moradias, especialmente por moradores de outros bairros.

As Habitações de Interesse Social que surgiram como ferramenta governamental para suprir a demanda, o déficit habitacional e a ilegalidade habitacional - além de movimentar setores da economia, favorecer empreiteiras, outras empresas e interesses locais, continuam mostrando-se obsoletas e de qualidade questionável tanto do ponto de vista urbanístico quanto arquitetônico, bem como na identificação, empatia e apropriação pelo morador e, igualmente, pelo não residente, sendo também responsável pela perpetuação de ideias equivocadas e pejorativas quanto a quem lá reside.

A este respeito, Lucini (2003, p.37) salienta que é necessário alterar a dinâmica em torno das HIS e torná-la mais atraente para os moradores, entendendo que eles vivem em uma condição que não é inerte e imutável e que sua habitação faz parte da sua identidade como cidadão:

O objetivo fundamental: transformar o sistema habitacional em uma estrutura suficientemente permeável às mudanças e à melhoria do perfil econômico e social do morador e do bairro, para possibilitar a médio e longo prazo o equilíbrio relativo entre segmentos sociais hoje fortemente segregados e distanciados na ocupação do espaço urbano. 


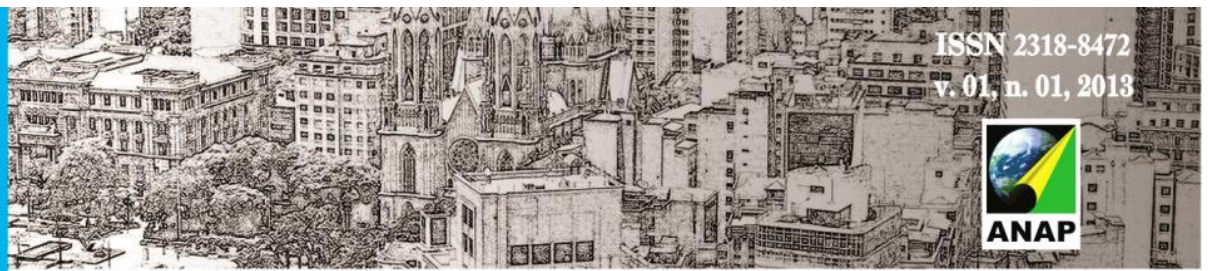

Revista Nacional de

Gerenciamento de Cidades

Dessa maneira, compreender esses fenômenos que envolvem a arquitetura e urbanismo, bem como a semiótica e a percepção ambiental é indispensável para, posteriormente, criar-se alternativas exitosas em relação às áreas de risco e HIS.

\section{MORFOLGIA URBANA E PERCEPÇÃO AMBIENTAL EM ÁREAS DE HIS}

A área do Promorar II, que nasceu como uma alternativa de Habitação de Interesse Social em Itajaí, cujo o objetivo era desfavelizar a comunidade Nossa Senhora das Graças, não foi totalmente bem-sucedida em seu propósito. Sabe-se que muitas famílias regressassem a localidade Nossa Senhora das Graças, abrindo mão do programa habitacional criado pelo poder público.

Tanto no Promorar II (em fundo de vale), quanto no Nossa Senhora as Graças (em encosta de morro), a morfologia foi fundamental na maneira de apropriação do espaço pelos moradores e é essencial na compreensão da apropriação deste espaço por habitantes de outros bairros.

A comunidade do Promorar II pertence a zona administrativa Cidade Nova e é limitada pelo rio Itajaí-Mirim. Nas décadas de 80 e nos anos de 2008 e 2011 área foi atingida por grandes enchentes, assim como outras áreas de Itajaí. Já a localidade Nossa Senhora das Graças, situa-se entre os bairros Centro, Dom Bosco e Fazenda, e é circunscrito por morros, que atualmente estão indevidamente ocupados.

A morfologia urbana decorrente da ocupação destas duas áreas com características distintas nem sempre foi igualmente diferenciada (MIRANDA e PEREIRA, 2011; SOUZA e PEREIRA, 2011), tendo implicado no tipo de apropriação nestes dois locais e é também fundamental para compreender a percepção urbana dos não- 

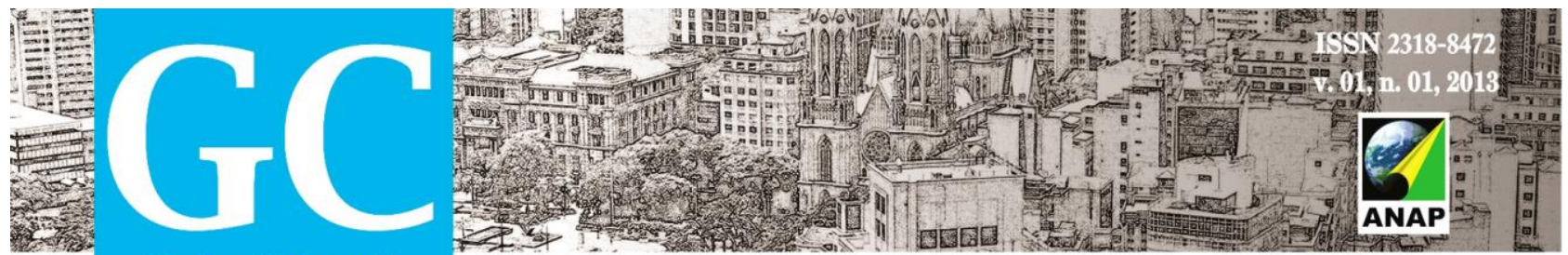

Revista Nacional de

Gerenciamento de Cidades

residentes em relação a HIS e, especificamente, ao Promorar II e Nossa Senhora das Graças.

A apreensão da forma urbana, com suas características e objetivos estéticos, é essencialmente realizada através dos sentidos humanos perpassados por processos de juízo imbricados à percepção (LAMAS, 2004, p.58), de maneira que "apesar da forma não se resumir aos aspectos sensoriais - portanto perceptíveis, estes são determinantes na sua compreensão", de modo que é neste âmbito que a semiótica pretende corroborar relacionando a percepção urbana e ambiental, destacando assim a importância da forma nos estudos intraurbanos, bem como das categorias de elementos que auxiliarão na realização desta tarefa, conforme detalha Lamas (2004), em seus os elementos morfológicos do espaço.

Porém, a maneira como se lê um determinado lugar não se restringe à morfologia urbana e a paisagem gerada em consequência. A percepção que se tem do espaço urbano vai muito além do aspecto visual e envolve a relação do indivíduo neste espaço a as transformações que nele ocorrem. "Essa transformação é a 'história do uso urbano como significado da cidade, sua vitalidade nos ensina o que o usuário pensa, deseja, despreza, a relação de suas escolhas, tendências e prazeres. A transformação da cidade é a história do uso do solo urbano escrita pelo usuário e o significado do espaço urbano é o desenvolvimento daquela recepção" (FERRARA, 1999, p.106).

\section{PERCEPÇÃO DOS RESIDENTES DA CIDADE LEGAL DE ITAJAÍ/SC: MÉTOdO DE TRABALHO}

Com o intuito de compreender a formação do imaginário e as percepções quanto a HIS e ao Promorar II e à Nossa Senhora das Graças foi feito entrevistas com residentes da cidade legal de Itajaí/SC baseadas em um roteiro semiestruturado. O critério para a escolha dos residentes entrevistados da cidade legal de Itajaí baseou-se 


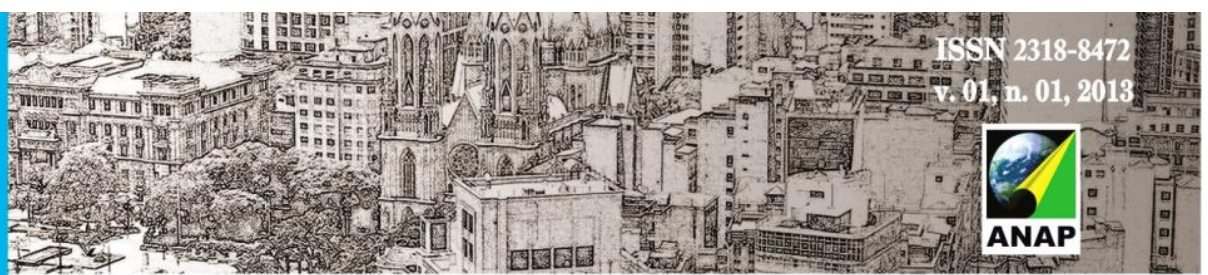

Revista Nacional de

Gerenciamento de Cidades

nos dados do Censo Demográfico de 2010 do Instituto Brasileiro de Geografia e Estatística (IBGE), - Tabela 1381 - que elencou o valor do rendimento nominal médio mensal das pessoas de 10 anos ou mais de idade e o valor do rendimento nominal mediano mensal das pessoas de 10 anos ou mais de idade dos bairros da cidade. Dessa forma, elencou-se os quatro bairros de Itajaí com maior renda, sendo eles por ordem decrescente: Bairro Cabeçudas, Bairro Centro, Bairro Vila Operária e Bairro Fazenda. Para fazer o mapeamento das áreas e cruzá-las com os dados do IBGE, utilizou-se a base do Mapa Urbano de Itajaí, com a divisão do perímetro urbano em Zonas Administrativas, determinadas pela Lei oㅜ 3359 de 21 de dezembro de 1998. Sendo elas, I - Zona Central (Centro), II - Zona Fazenda, III - Zona Cabeçudas, IV - Zona Praia Brava, V - Zona Ressacada, VI - Zona Cidade Nova, VII - Zona São Vicente, VIII - Zona Dom Bosco, IX - Zona Vila Operária, X - Zona São João, XI - Zona Barra do Rio, XII Zona Cordeiros, XIII - Zona Salseiros, XIV - Zona Espinheiros, XV - Zona Itaipava, XVI Zona Canhanduba. A Lei no 3673 de 10 de dezembro de 2001 cria a Zona Administrativa São Judas. Conforme a Secretaria Municipal de Urbanismo de Itajaí (SMU), Murta, Volta de Cima, Espinheirinhos, São Roque, Rio Novo/Colônia Japonesa, Km 12 e Rio do Meio são localidades de Itajaí, não reconhecidas como zonas administrativas, segundo as leis citadas anteriormente. Conclui-se, portanto, que esta é a razão pela qual essas localidades não foram identificadas pelo Censo 2010 do IBGE na tabela 1381 e, sendo assim, não mapeadas. 



Revista Nacional de

Gerenciamento de Cidades
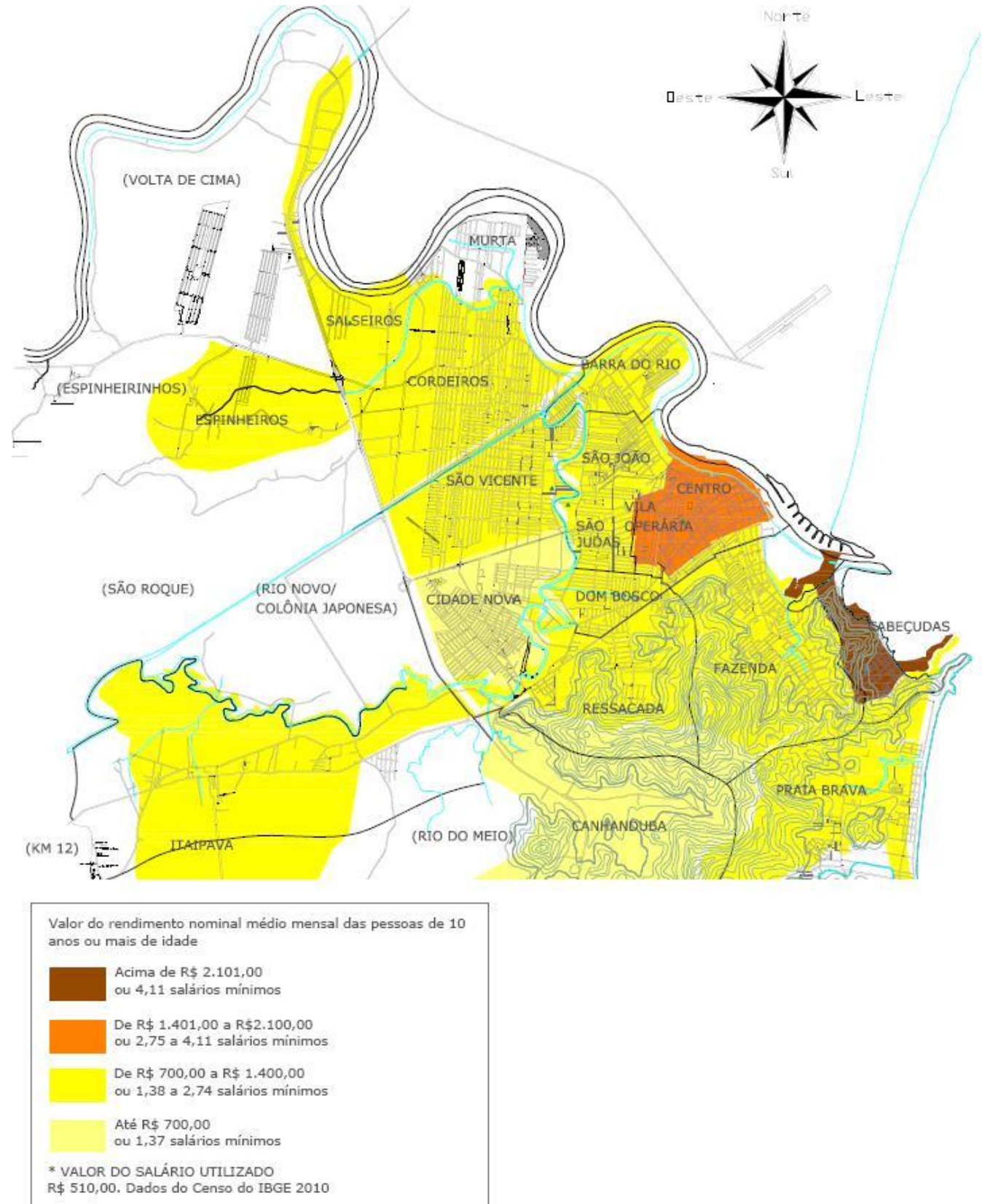

Figura 01: Mapa Urbano de Itajaí com valores do rendimento, conforme o IBGE. Fonte: A autora, 2012. 

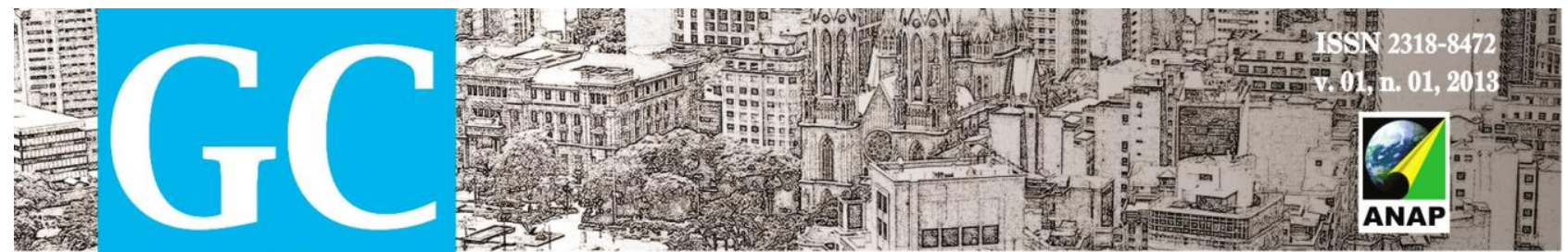

Revista Nacional de

Gerenciamento de Cidades

A partir destas informações, onze entrevistados dos bairros Cabeçudas, Centro, Vila Operária e Fazenda foram escolhidos de maneira aleatória.

Partiu-se do princípio que os entrevistados necessariamente não seriam moradores das áreas pesquisas e, portanto, talvez não conhecessem tais locais, sendo assim, foram previamente selecionadas 32 imagens que posteriormente foram apresentadas aos entrevistados. As imagens carregam consigo uma visão de ideia do que são área de interesse social independentemente do lugar que representam.

Os entrevistados deveriam responder ao questionário e depois eleger as mais semelhantes com o que pensam ser áreas de habitação de interesse social e, especificamente, as figuras mais parecidas com o que imaginam ser as áreas Nossa Senhora das Graças e Promorar II. As imagens foram retiradas da internet, arquivo pessoal da pesquisadora e arquivo pessoal da orientadora. Algumas imagens são, de fato, das comunidades Nossa Senhora das Graças e Promorar II. Cada entrevistado escolheu três imagens, sendo que dois entrevistados indicaram 10 e seis imagens, respectivamente.

\section{PERCEPÇÃO DOS RESIDENTES DA CIDADE LEGAL DE ITAJAÍ/SC: ANÁLISE DOS DADOS}

Para fazer esta análise levou-se em consideração conceitos básicos da semiótica peirceana, baseada nos conceitos de Charles Sanders Pierce.

Peirce delimitou três elementos em todos os fenômenos (tudo aquilo, qualquer coisa, que aparece à percepção e à mente): signo, objeto e interpretação. Santaella (2002, p.9) exemplifica: "[...] um vídeo de educação ambiental sobre o desmatamento da região amazônica é um signo que tem por objeto a região retratada no vídeo. Os efeitos interpretativos que o vídeo produz em seus espectadores é o interpretante do signo". No caso analisado, o signo seriam as próprias fotos. O objeto são as imagens nestas 
fotos: as áreas de interesse social, bairros, situações cotidianas, ruas, iluminação pública, entre outros. E a interpretação é a percepção de cada entrevistado sobre as imagens apresentadas, tendo em vista, suas experiências, onde moram, sua profissão.

Das 32 imagens apresentadas, dezessete imagens foram escolhidas por mostrarem aspectos positivos (coleta de lixo, ruas limpas, vizinhos alegres conversando, áreas de lazer, crianças brincando, ruas asfaltadas, prédios e casas organizados com tipologia semelhantes e bem pintados, obra de infraestrutura) do espaço urbano e quinze imagens com aspectos negativos (ruas mal iluminadas, muros pichados adolescentes encapuzados, crianças mal vestidas, áreas de lazer e mobiliário urbano deteriorados, esgoto a céu aberto, lixo na rua, vias sem pavimentação e sem passeio público, ocupações ilegais em encosta de morro, habitações próximas a rios sujeitas à enchentes). A divisão entre imagens positivas e negativas está atrelada ao que dispõem o Estatuto da Cidade, Lei n 10.257, de 10 de julho de 2001. O Estatuto da Cidade

[...] estabelece normas de ordem pública e interesse social que regulam o uso da propriedade urbana em prol do bem coletivo, da segurança e do bem-estar dos cidadãos, bem como do equilíbrio ambiental. (...) Art. 2: I - garantia do direito a cidades sustentáveis, entendido como o direito à terra urbana, à moradia, ao saneamento ambiental, à infra-estrutura urbana, ao transporte e aos serviços públicos, ao trabalho e ao lazer, para as presentes e futuras gerações; (...) V oferta de equipamentos urbanos e comunitários, transporte e serviços públicos adequados aos interesses e necessidades da população e às características locais (BRASIL, 2001).

Dessa maneira, entende-se que é de direito dos cidadãos saneamento, infraestrutura, serviços públicos e lazer. As imagens condicionadas como negativas ferem ao texto do estatuto.

Além disso, pessoas sorrindo e alegres são alusivas a uma boa qualidade de vida, que está intrinsecamente ligada à qualidade do espaço urbano, ou seja, qualidade da paisagem ligada ao desenvolvimento social. 
Santos (1997) afirma que enquanto a paisagem corresponde ao uma porção territorial mais inerte, o espaço é definido pela colaboração humana nesta paisagem.

A paisagem é o conjunto de formas que, num dado momento, exprimem as heranças que representam as sucessivas relações localizadas entre homem e natureza. O espaço são essas formas mais a vida que as anima. (...) A rigor, a paisagem é apenas a porção da configuração territorial que é possível abarcar com a visão. (...) Neste sentido, a paisagem é transtemporal, juntando objetos passados e presentes, uma construção transversal. O espaço é sempre um Presente, uma construção horizontal, uma situação única. Cada paisagem se caracteriza por uma dada distribuição de formas-objeto, providas de um conteúdo técnico específico. Já o espaço resulta da intrusão da sociedade nessas formasobjetos (SANTOS, 1997, p.83).

\section{INFORMAÇÕES OCULTAS: AS IMAGENS QUE NÃO FORAM ASSOCIADAS}

Das doze imagens não escolhidas pelos entrevistados, oito são positivas: os registros mostram infraestrutura, coleta de lixo, vizinhos convivendo amistosamente, pessoas sorrindo, entre outros. Ou seja, a maioria das imagens não selecionadas mostra aspectos urbanos e arquitetônicos salutares, bem como, indivíduos satisfeitos e felizes. Considera-se que a eleição feita pelos entrevistados dos quatro bairros com maior renda de Itajaí tende a relacionar áreas de interesse social e, nomeadamente, o bairro Nossa Senhora das Graças e Promorar II com espaços precários e com pouca infraestrutura.

\section{RELAÇÕES ESTABELECIDAS ATRAVÉS DAS IMAGENS SELECIONADAS}

A imagem 13 (negativa), foi selecionada cinco vezes. Na fala dos entrevistados há uma unanimidade em relacionar a imagem às enchentes que aconteceram no Estado nos anos 80 e mais recentemente, 2008 e 2011. Os entrevistados, embora alguns não 


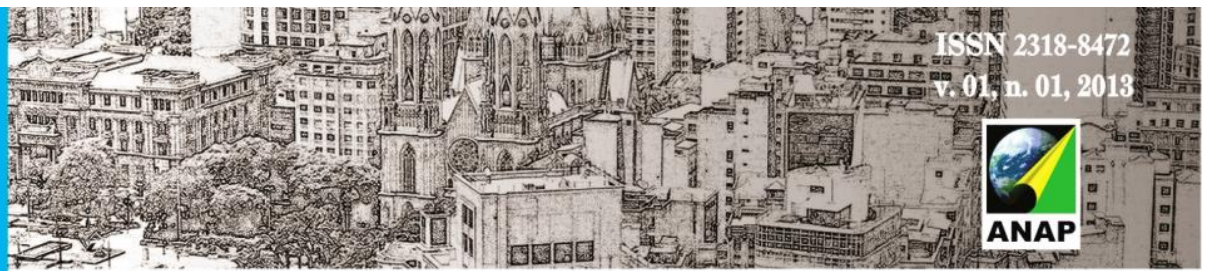

Revista Nacional de

Gerenciamento de Cidades

soubessem que a imagem faz parte da área do Promorar II, facilmente relacionaram a foto com os acontecimentos presentes.

Outra imagem que foi selecionada mais de uma duas vezes é a imagem 2 e a imagem 26. A imagem 2 (negativa), escolhida quatro vezes, mostra um esgoto a céu aberto e crianças brincando próximas a ele. Já a imagem 26 (positiva), também selecionada quatro vezes, mostra uma rua no Promorar II, asfaltada com poucos equipamentos urbanos e sem moradores próximos.

As demais imagens, escolhidas menos de quatro vezes, foram oito positivas e nove negativas. Considera-se que os aspectos negativos foram arraigados com áreas de habitação de interesse social muito mais que aspectos positivos. Embora a maioria dos entrevistados não tivesse definição sólida sobre o que é uma área de interesse social, existe a relação diretamente às áreas de lazer.

Os entrevistados também imaginam os aspectos físicos e sensações desses locais com pouca infraestrutura e insegurança.

\section{PERCEPÇÃO URBANA DAS ÁREAS DE HIS POR RESIDENTES DA CIDADE LEGAL DE ITAJAÍ/SC}

A percepção urbana pelos moradores dos bairros Cabeçudas, Centro, Vila Operária e Fazenda em relação às comunidades Nossa Senhora das Graças e Promorar Il faz parte do imaginário coletivo dos entrevistados. Muitos deles nunca entraram, de fato, nesses locais, entretanto apresentaram opiniões formadas sobre essas áreas. Os resultados corroboram com o que cita Ferrara (1999). "[...] a percepção urbana não é um dado, não se manifesta como uma certeza, mas é um processo e uma possibilidade. Altera-se conforme as características socioculturais e informativas (repertório) do morador 



Revista Nacional de

Gerenciamento de Cidades

da cidade e submete-se às características físicas, econômicas e de infra-estrutura do próprio espaço urbano" (FERRARA, 1999, p. 107).

A insegurança e constantes assaltos também foram recorrentes nas entrevistas, especialmente em relação ao bairro Nossa Senhora das Graças.

Entretanto, conforme dados do 1ํㅡㄹathão de Polícia Militar de Itajaí referentes a homicídios, roubo a estabelecimento comercial e assalto contra pessoa dos anos de 2010 até dia 12 de novembro de 2012, o Bairro Nossa Senhora das Graças apresentou sete homicídios nos três últimos anos, nenhum roubo a estabelecimento comercial e seis assaltos contra pessoa.

O bairro Promorar II, que faz parte da Cidade Nova - conforme informação do $1^{\circ}$ Batalhão de Polícia Militar, correspondente ao registro do bairro São Vicente. Segundo a entidade, o sistema da PM é desatualizado e difere da divisão estabelecida pelo Poder Executivo. Sendo assim, muitas localidades, que não são reconhecidas como zonas administrativas, mas que são subdivisões espontâneas feitas pelos próprios moradores, constam no banco de dados da PM. O bairro São Vicente apresenta 26 ocorrências de homicídios, 201 roubos a estabelecimentos comerciais e 248 assaltos contra pessoa. Os números de ocorrências relativos ao Bairro Nossa Senhora das Graças são inferiores a outros bairros, como o Bairro Cordeiros que apresentou 25 homicídios nos últimos três anos. O bairro Centro registrou 243 ocorrências de assalto contra pessoa nos anos de 2010 a final de 2012. Embora o Nossa Senhora das Graças foi citado com um local violento e inseguro, de acordo com as informações da Polícia Militar, ele registrou menos ocorrências que o bairro São Vicente, onde situa-se o Promorar II. 

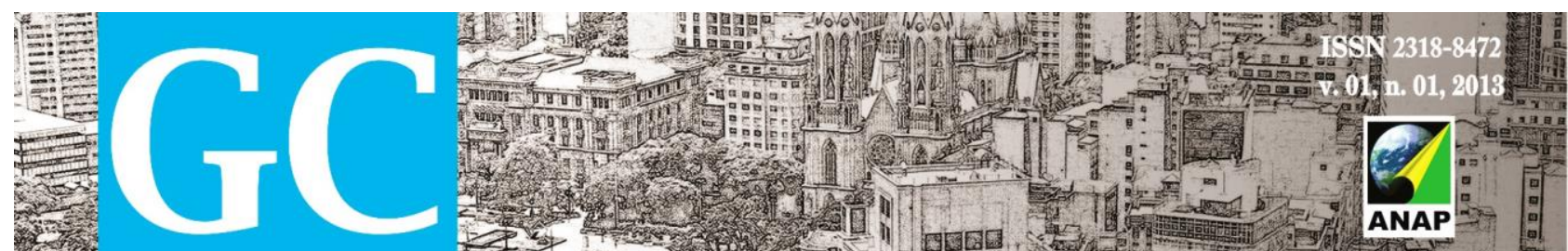

Revista Nacional de

Gerenciamento de Cidades


*Dados do 10 Batalhão de Polícia Militar de Itajai/SC

Figura 02: Homicídios registrados pelo 1 Batalhão de Polícia Militar de Itajaí.

Fonte: A autora, 2012. 


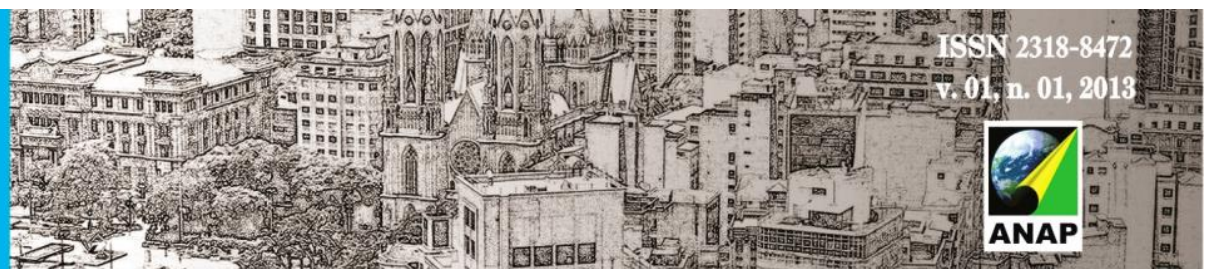

Revista Nacional de

Gerenciamento de Cidades

O bairro Cordeiros e o Bairro São Vicente (que engloba, na divisão do 1 Batalhão de Polícia Militar de Itajaí, o bairro Cidade Nova, onde situa-se o Promorar II) são os mais violentos, com mais de 20 homicídios registrados.

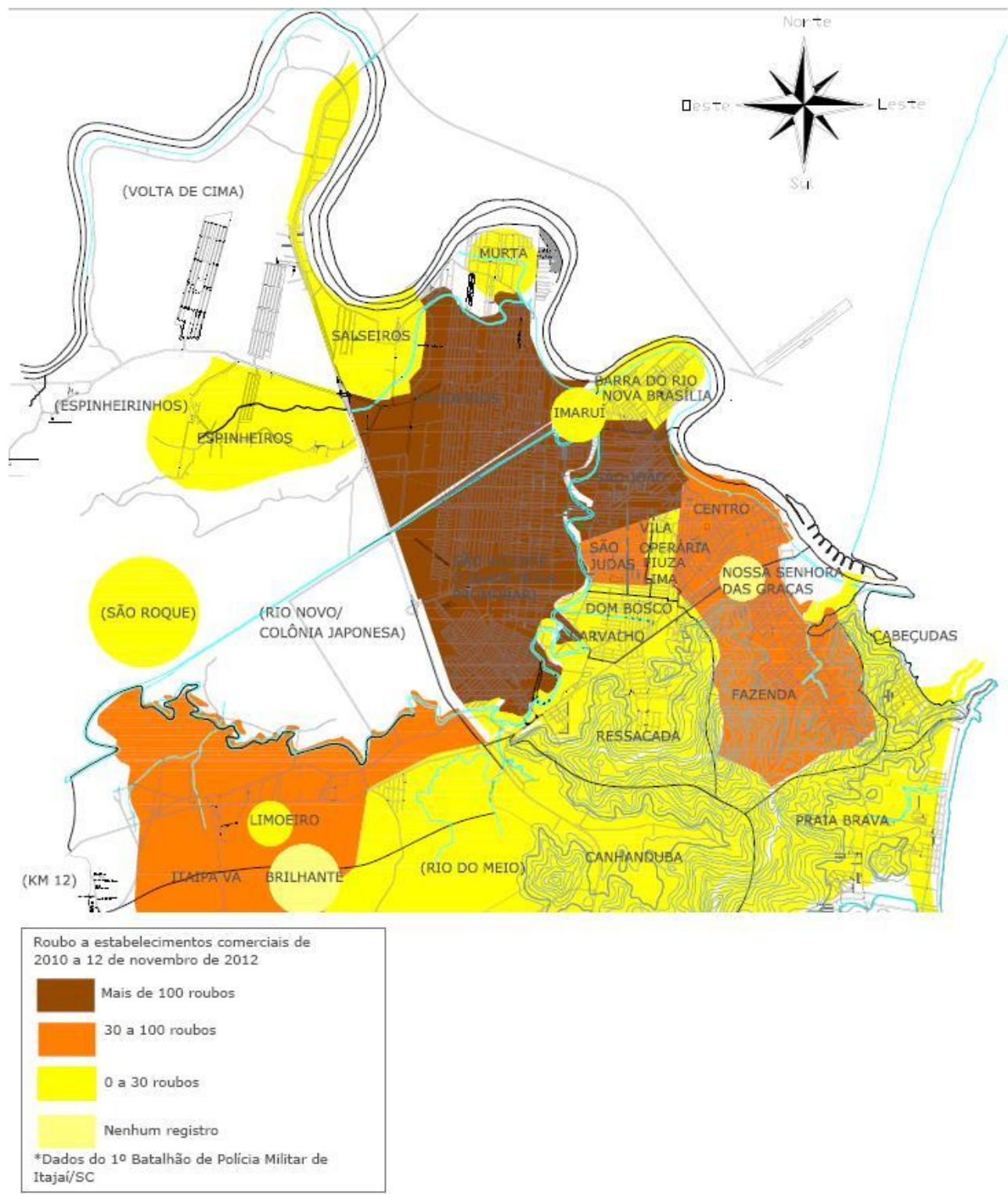

Figura 03: Roubo a estabelecimentos comerciais registrados pelo 1 Batalhão de Polícia Militar de Itajaí.

Fonte: A autora, 2012. 


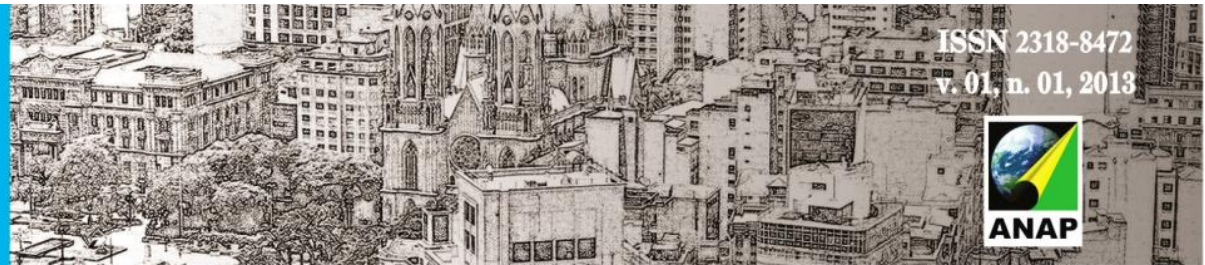

Revista Nacional de

Gerenciamento de Cidades

Desta vez, além dos bairros Cordeiros e São Vicente, o bairro São João são os que apresentaram mais registros de ocorrência quanto a roubos em estabelecimentos comerciais. Enquanto a comunidade Nossa Senhora das Graças não registrou nenhuma ocorrência relativa a roubos de estabelecimentos comerciais em três anos consecutivos.

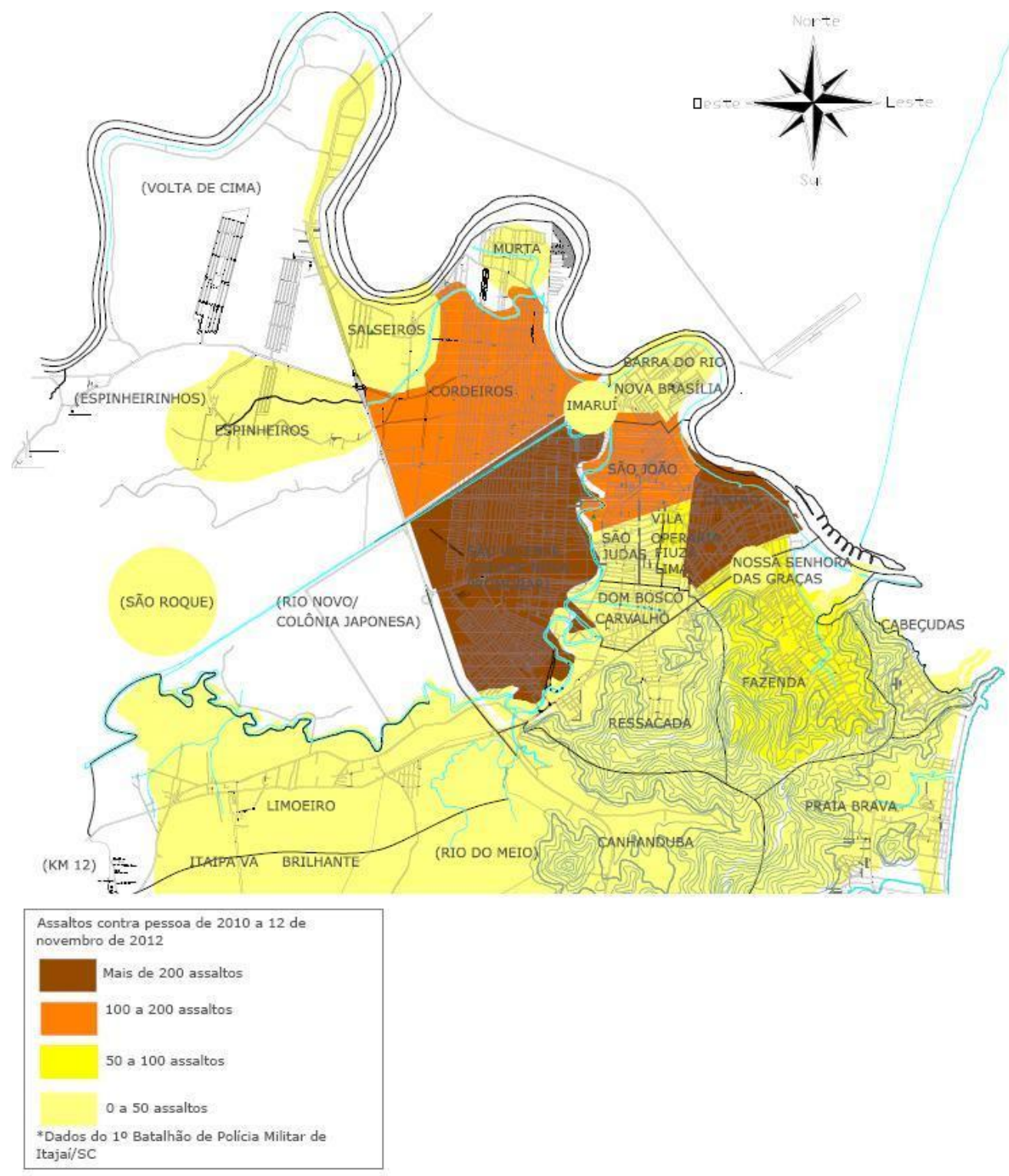

Figura 03: Assalto contra pessoa registrados pelo 1 Batalhão de Polícia Militar de Itajaí. Fonte: A autora, 2012. 


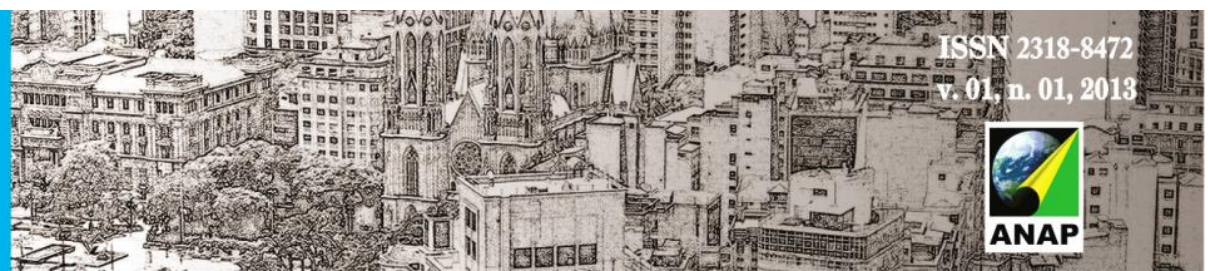

Revista Nacional de

Gerenciamento de Cidades

Novamente, o bairro São Vicente (que está envolvendo a zona Cidade Nova, onde localiza-se o Promorar) apresenta mais ocorrências de assalto contra pessoa do que a comunidade de Nossa Senhora das Graças. Embora, este último tenha sido considerado pelos entrevistados mais violento e inseguro.

\section{ELEMENTOS MORFOLÓGICOS E SOCIOCULTURAIS IDENTIFICADOS PELOS RESIDNETES DA CIDADE LEGAL}

$\mathrm{Na}$ área do Nossa Senhora das Graças existe o presídio regional de Itajaí. O presídio, inclusive, foi um aspecto da paisagem urbana recorrente na fala dos moradores da cidade legal, sendo citado três vezes. A localização do presídio na comunidade é fundamental para que a área seja considerada perigosa e inóspita. O presídio é um signo relevante para toda a cidade e é relacionado com assalto, roubo e homicídio. Entretanto, conforme os dados do 1 Batalhão da PM, a comunidade Nossa Senhora das Graças, nos últimos três anos apontou registros ínfimos de homicídios, roubos a estabelecimentos comerciais e assaltos contra pessoa.

Em relação ao Promorar II, a morfologia espacial, limitada pela hidrografia foi recursivo no discursos dos entrevistados. À relação entre arquitetura, hidrografia, cheias, enchentes apareceu seis vezes nos discursos.

O Parque Dom Bosco foi citado três vezes como elemento significativo em Itajaí, relacionado com lazer e bem-estar. Lamas (2004) define as praças/parques como espaços dedicados intencionalmente ao lazer e importantíssimos na construção da cidade 


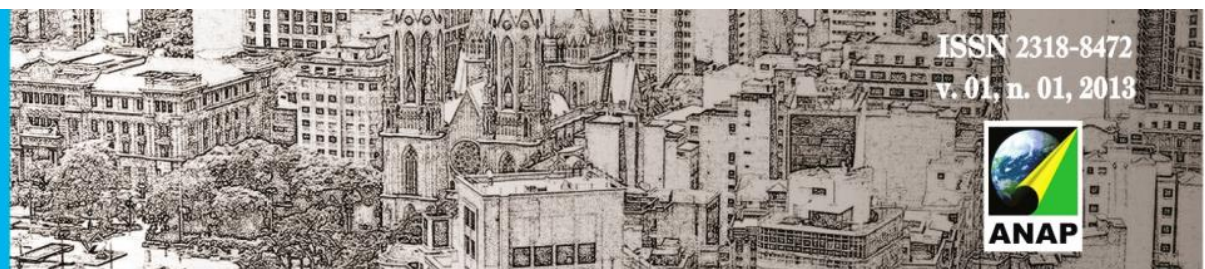

Revista Nacional de

Gerenciamento de Cidades

e nas relações sócias. Em alguns discursos o Parque Dom Bosco ou o Presídio Regional de Itajaí aparecem como monumento.

\section{OUTRAS CONSIDERAÇÕES}

A morfologia urbana é fundamental na apropriação de um espaço e também na maneira como o indivíduo que dele se apropria é visto pelos demais. Percebe-se que, embora o Nossa Senhora das Graças seja menos violento e inseguro que demais bairros, ele carrega o estigma de violento. Isso diz muito mais sobre o imaginário coletivo dos moradores de Itajaí do que com a realidade atual.

A arquitetura funciona e é um signo. De uma intervenção urbanística, obra, edificação se extrai significado. Este significado, por sua vez, está intrinsecamente ligado às experiências de quem a está interpretando.

Nesse sentido, percebeu-se que a profissão dos entrevistados e os locais pelo qual circula na cidade são decisivos para a compreensão do espaço urbano e das áreas Nossa Senhora das Graças e Promorar. Bem como jornais, revistas, programas de rádio e televisão têm um papel forte em relação ao que permeia a percepção sobre determinado local. 


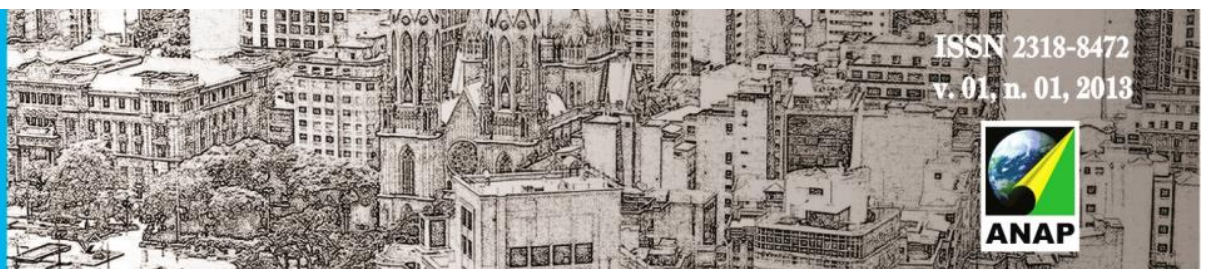

Revista Nacional de

Gerenciamento de Cidades

\section{REFERÊNCIAS}

BRASIL. Estatuto da Cidade. Lei oㅜ 10.257, de 10 de julho de 2001. Disponível em: <http://www.planalto.gov.br/ccivil_03/leis/LEIS_2001/L10257.htm>. Acessado em: $1 / 02 / 2013$.

FERRARA Lucrécia D'Alessio. Olhar periférico. São Paulo: Editora da Universidade de São Paulo, 1999.

LAMAS, José M. Ressano Garcia. Morfologia urbana e desenho da cidade. Lisboa [Portugal] : Fundação Calouste Gulbenkian, 2004.

LUCINI, Hugo Camilo. Habitação social: procurando alternativas de projeto. Itajai: Universidade do Vale do Itajaí, 2003.

MIRANDA, Paloma Schlösser de e PEREIRA, Luciana Noronha. Tipologias arquitetônicas em áreas de habitação de interesse social: percepção, apropriação e construção/alteração de unidades habitacionais pela população residente. Artigo apresentado como relatório final de pesquisa do Artigo 170 (28p.). Univali: Balneário Camboriú, 2011.

PREFEITURA DE ITAJAÍ. Leis Municipais. Lei ํㅜ 3673 de 10 de dezembro de 2001. Disponível em: <http://www.leismunicipais.com.br/cgi-local/showinglaw.pl>. Acessado em: 5/02/2013.

PREFEITURA DE ITAJAÍ. Jus Brasil. Lei 3359/98. Lei o 3359 de 21 de dezembro de 1998 de Itajaí. Disponível em: <http://www.jusbrasil.com.br/legislacao/763010/lei-3359-98itajai-0>, Acessado em 5/02/2013.

SANTAELLA, Lucia. Semiótica aplicada. São Paulo: Thomson, 2002. 


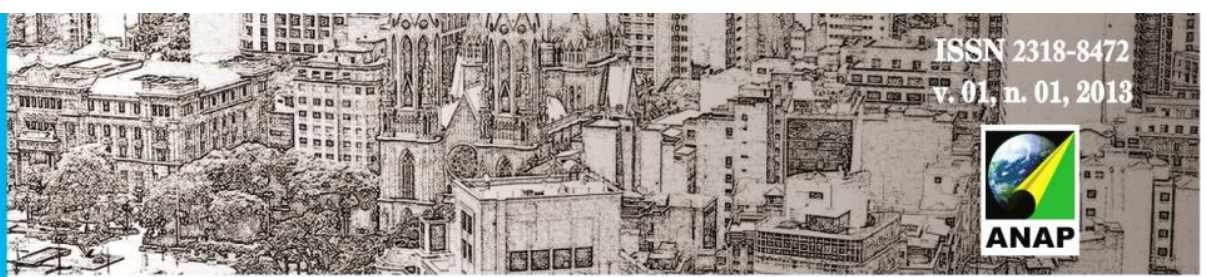

Revista Nacional de

Gerenciamento de Cidades

SANTOS, Milton. A natureza do espaço: técnica e tempo, razão e emoção. São Paulo, SP: Hucitec, 1997.

SOUZA, Aline Terras e PEREIRA, Luciana Noronha. Morfologia urbana e apropriação do espaço pelas populações residentes: a importância da imagem na compreensão do sistema urbano em áreas de habitação de interesse social. Artigo apresentado como relatório final de pesquisa do Artigo 170 (33 p.). Univali: Balneário Camboriú, 2011. 